\title{
Care for patients with advanced cancer in the last weeks of life in Brazil
}

Atendimento a pacientes com câncer avançado nas últimas semanas de vida no Brasil

David Hui', Camilla Zimmermann², Ana Lúcia Coradazzi³, Theodora Karnakis ${ }^{4}$, Natália Nunes ${ }^{5}$, Isabella Gattás ${ }^{4}$, Mirza Jacqueline Alcade Castro², Ricardo Caponero ${ }^{6}$

\begin{abstract}
Despite all advances in the treatment of neoplasms and substantial increases in fiveyear survival rates, most patients still die due to their diseases. Late diagnosis in some circumstances and resistance mechanisms throughout treatment still cause most patients to require palliative care integrated with cancer treatment, since diagnosis. Most palliative care interventions can and should be carried out by the oncologist, with reference to the multidisciplinary team specialized in palliative care in the most critical moments of clinical evolution. It is important that the oncologist develops their skills in this scenario and knows how to recognize the moment of referral. The following text outlines the basic skills that are expected of oncologists, such as recognition of the prognosis, identification and correct assessment of symptoms, definition of the time to stop antineoplastic therapy, how to communicate these aspects to patients and family, how to involve psychosocial and spiritual issues and, finally, how to stay within the limits established by modern bioethics. This work consists of brief recommendations for oncologists working in Brazil. Headings: Terminal care; Death; Palliative care; Palliative medicine.
\end{abstract}

\footnotetext{
1. MD Anderson Cancer Center - USA, Palliative Care - Texas - Houston - United States.

2. Princess Margaret Cancer Centre, Medicine - Toronto - Toronto - Canada.

3. UNESP (Faculdade de Medicina de Botucatu - UNESP - Brasil)., Medical Oncology - Botucatu - Sao Paulo - Brazil.

4. Instituto do câncer do Estado de São Paulo - Brasil, Geriatry - Sao Paulo - Sao Paulo - Brazil.

5. Instituto Nacional do Câncer - INCA, Palliative Care - Rio de Janeiro - Rio de Janeiro - Brazil.

6. Hospital Alemão Oswaldo Cruz, Centro Especializado em Oncologia - São Paulo - São Paulo - Brazil.

Financial support: none to declare.

Conflicts of interest: The authors declare no conflict of interest relevant to this manuscript.

Correspondence author: Ricardo Caponero.

E-mail: r.caponero@gmail.com
} 


\section{RESUMO}

Apesar de todos os avanços no tratamento das neoplasias e aumentos substanciais nas taxas de sobrevida em cinco anos, a maioria dos pacientes ainda morre em decorrência de suas doenças. Diagnósticos tardios em algumas circunstâncias e mecanismos de resistência ao longo do tratamento ainda fazem com que a maioria dos pacientes necessite de cuidados paliativos integrados ao tratamento oncológico, desde o diagnóstico. A maioria das intervenções em cuidados paliativos pode e deve ser realizada pelo oncologista, tendo como referência a equipa multidisciplinar especializada em cuidados paliativos nos momentos mais críticos da evolução clínica. É importante que o oncologista desenvolva suas habilidades nesse cenário e saiba reconhecer o momento do encaminhamento. $O$ texto a seguir descreve as habilidades básicas que são esperadas dos oncologistas, como reconhecimento do prognóstico, identificação e avaliação correta dos sintomas, definição do momento de interromper a terapia antineoplásica, como comunicar esses aspectos aos pacientes e familiares, como envolver questões psicossociais e espirituais e, por fim, como se manter dentro dos limites estabelecidos pela bioética moderna. Este trabalho consiste em breves recomendações para oncologistas atuantes no Brasil.

Descritores: Cuidados terminais; Morte; Cuidado paliativo; Medicina paliativa.

\section{INTRODUCTION}

\section{Introduction to general concepts of palliative care in oncology}

In the last weeks and days of life, patients with advanced cancer often experience characteristic decline in function, coupled with an abrupt increase in physical symptoms, psychological distress and care needs. Acute complications are common which may require hospitalization. (1) Patients, families and clinicians are faced with many difficult decisions regarding care planning, cancer treatments, and discharge. Oncologists often have a strong relationship with patients from diagnosis and have a critical role alleviating suffering as their patients approach the final phase of life.

Because of the high complex needs during this time, it is often helpful for the oncology team to involve other health professionals to support the multi-dimensional needs of patients and families during this time. (2) For example, interdisciplinary specialist palliative care teams have significant expertise in managing complex symptoms, supporting personhood care, and facilitating complex decision making. Psychiatry, psychology, social work, and/or chaplaincy can provide effective interventions for mood disorders, death anxiety, existential distress and/or anticipatory grief.

Palliative care is defined by the World Health Organization as "is an approach that improves the quality of life of patients (adults and children) and their families who are facing problems associated with life-threatening illness. It prevents and relieves suffering through the early identification, correct assessment and treatment of pain and other problems, whether physical, psychosocial or spiritual".(3) Although cancer patients are often referred to palliative care in the final phase of life, it is important to note that existing evidence strongly supports involvement of palliative care early in the disease trajectory. ${ }^{(4)}$
Several landmark randomized trials and systematic reviews found that timely referral of patients with advanced cancer to outpatient palliative care from around the time of diagnosis can improve their quality of life, symptom control, mood, communication, satisfaction, and quality of end-of-life. ${ }^{(5-9)}$ In addition to the ambulatory setting, palliative care may be available in the hospital as an inpatient consultation service and/or a palliative care unit (i.e., intensive supportive care unit). In the community, palliative care may also offer home palliative care service and/or hospice care.(10) Thus, different branches of specialist palliative care teams may be deployed to support the patients and their families tailored to the setting and level of care needs.

Oncologists caring for patients in the last weeks/days of life should be comfortable in core primary palliative care competencies (i.e., basic symptom management and communication skills). ${ }^{(1)}$ Patients with greater care needs should have access to interdisciplinary specialist palliative care teams. In this clinical guideline, we shall provide a practical overview of key considerations in the management of patients with advanced cancer approaching the end-of-life, including: (1) how to recognize patients are approaching the final weeks/days of life, (2) cancer treatment decisions, (3) management of physical symptoms, (4) addressing psychological distress, (5) spirituality, (6) caregiver care, (7) refractory symptoms, (8) communication issues, (9) ethical and legal aspects and (10) overcoming barriers to providing quality of end-of-life care.

How to recognize patients that are approaching the final weeks/days of life. The ability to recognize that a patient with advanced cancer has entered the final weeks or days of life is of paramount importance. ${ }^{(12)}$ First, the clinician can communicate the outlook with the patient and his/her family. ${ }^{(13)}$ Second, the patient and family can take advantage of this information to make preparations for his/her personal life as well as healthcare decisions. 
For example, studies have found that cancer patients who understood they had a short life expectancy were less likely to want to pursue chemotherapy than patients who believed they had a longer life expectancy. ${ }^{(14)}$ Third, the oncology team would be able to make better recommendations based on the patients' prognosis. ${ }^{(15)}$

In the advanced cancer setting, multiple prognostic factors have been identified. In the final weeks and months of life, patients with advanced cancer often develop a progressive decline in their physical function, nutritional balance, respiratory status and cognitive abilities, which typically manifest as decreased performance status (e.g., Zubrod ECOG performance status 23), anorexia-cachexia, dyspnea at rest and delirium, respectively. ${ }^{(16)}$ The presence of these symptoms in the context of refractory cancer is highly suggestive that the patient has a life expectancy of several months or less. Other well established prognostic factors include leukocytosis, lymphocytopenia, elevated lactate dehydrogenase, hypoalbuminemia, and elevated C-reactive protein are laboratory-based. ${ }^{(17)}$

Several prognostic scores are available in the advanced cancer setting that incorporate many of the above prognostic factors, such as the palliative prognostic score and palliative prognostic index. ${ }^{(18,19)}$ These prognostic models may augment prognostication and help to stratify patients in the good (months of survival), intermediate (weeks of survival) and poor risk (days of survival) groups. The literature has found that prognostic models are at least as accurate as clinician's prediction and may sometimes be more accurate. $(20,21)$ Web-based calculators are available to facilitate computation and interpretation of these prognostic scores (www.predictsurvival.com). ${ }^{(22)}$ More recently, machine learning algorithms are being developed to support prognosis-based decision-making. ${ }^{(23)}$

In the final days and hours of life, cancer patients often develop further deterioration in their neurological, neuromuscular, and cardiovascular function, (24,25) which may manifest as follows:

- Neurological changes: decreased responsiveness to verbal and visual stimuli, Cheyne Stokes breathing, apnea periods;

- Neuromuscular changes: inability to clear secretions (death rattle), inability to close eyelids, drooping of nasolabial fold, respiration with mandibular movement, hyperextension of neck;

- Cardiovascular changes: oliguria or anuria, pulselessness of radial artery, severe hypotension, peripheral cyanosis.

These "tell-tale" signs of impending death generally have a high specificity but low sensitivity for impending death within the next 3 days. ${ }^{(26,27)}$ Thus, the presence of any these signs in the appropriate context strongly supports the diagnosis of impending death; however, the absence of these signs cannot be used to rule out impending death. A diagnostic model is available with accuracy of over $80 \%$. $^{(28)}$

\section{When to consider stopping cancer treatments?}

Decision-making around starting and stopping treatment in advanced cancer is challenging for patients, families, and healthcare professionals. Appropriately timed cessation of treatment is an internationally recognized cancer treatment quality indicator, ${ }^{(29-31)}$ yet recent years have seen a trend towards continuing treatment until close to the end of life, at times within weeks till death. ${ }^{(32,33)}$ Current guidelines set out when to start anticancer treatments, but not when to stop as the end-of-life approaches. The process of treatment withdrawal was described as a shared progression of many different conversations rather than a one-off decision. ${ }^{(34-36)}$ Frequently, it involves a trajectory of repeated reassessments and trying different treatment options including treatment breaks, before completing withdraw. ${ }^{(37)}$

Cancer treatment decision making involves timely, high-risk, life altering shared decision-making conversations between patients, their families, and their medical team. As such, these conversations are a prime target for a carefully designed, easy to interpret approach to facilitate preference-sensitive decision making. ${ }^{(38)}$ It has been described the needs and preferences of cancer patients including the type and amount of information patients prefer, the main sources of information that patients use, and the various ways that patients seek out information. ${ }^{(38)}$ Despite this vast research literature, understanding how to discuss stopping treatment and engage patients in decision-making regarding their treatment remains a great challenge for many physicians. ${ }^{(38-40)}$

Oncologists commonly report finding discussions about stopping treatment difficult( ${ }^{(34-36)}$ and emotionally challenging. ${ }^{(41)}$ There is general consensus that physicians caring for critically ill patients have an obligation to disclose information about a patient's medical condition and prognosis to family members, and also that family members are an important source of information about the patient's values and treatment preferences. Furthermore, there is consensus that family members' fulfilling this role should be counseled to use the principle of substituted judgment to guide decisions when possible, attempting to answer the question of what the patient would say if they are able to participate. ${ }^{(42)}$

Although a number of distinct approaches to conceptualizing the physician-patient relationship have been proposed, traditionally there are three distinct ways described:(42) (1) parentalism, in which the physician makes the treatment decision with little input from the patient or family; (2) informed choice, in which the physician provides all relevant medical information but withholds his or her opinion and places responsibility for the decision on the family; (3) shared decision-making, in which the physician and family each share their opinions and jointly reach a decision.

Shared decision-making is complex and requires patients to understand and process complex medical information and then be able to examine and evaluate all available treatments options to make personally appropriate decisions. ${ }^{(41)}$ 
This can be a big challenge when discussing discontinuation cancer treatment. Planning end-of-life care is an iterative or cyclic process based on assessment, disclosure, discussion, and consensus building with the patient and/or their family and the treatment team. This process can take place over a short period, such as hours, where the patient suddenly or unexpectedly deteriorates, but it can also extend over weeks or months. ${ }^{(41,42)}$

It is important to know when it is appropriate to end oncologic treatment to maintain the best quality of life. The criteria for discontinuation of anti-cancer therapy are often "exacerbation of patient's condition," "problems with toxicity," or "patient refusal". However, there is no clear agreement regarding when to end oncologic treatment. Adding to the complexity of this process, prior research indicates that there is great variability in the degree to which patients prefer to be involved in stopping their oncologic treatment. Thus, clinicians must be sensitive to these potential individual differences when negotiating proposed treatments with patients and their families. ${ }^{(41,42)}$

Therefore, timely and appropriate decision-making about end-of-life care is more likely where those close to the patient understand the patient's wishes in advance. With discussion and planning, the patient's preferences and values can inform decision- making as priorities change during the time leading to the patient's death. Included in these shared decision-making models is the acknowledgement that clinicians and patients may have different values and preferences affecting their preferred course of treatment. Thus, as noted, the goal of shared decision-making is negotiation and consensus-building on what the appropriate treatment is and when the treatment no longer benefits the patient not only in survival but mainly in quality of life.

\section{Communication at the end-of-life}

(1) General communication skills. What are the basic principles of effective patient-clinician communication in cancer care?

- $\quad$ Getting prepared. ${ }^{(43)}$

It is essential to review the clinical information to prepare for patient and family needs for responses. Preliminary establish the goal for the upcoming appointment.

Acknowledge communication preferences. ${ }^{(44-46)}$

Parties involved in health care communication come from diverse backgrounds (e.g., generational, socioeconomic). However, it is essential to elicit individual communication preferences rather than assuming that these falls neatly into a specific category. At the beginning of the clinical encounter, it is appropriate to query whether there are any cultural or individual preferences that one should be aware of as a health care provider. A useful mnemotechnics to address communication preferences is the FIFE model (feelings, ideas, function and expectations).
- $\quad$ Active and empathetic listening. (43-49)

Clinician-patient communication has verbal and non-verbal components. It is important to recognize and respond to non-verbal cues, listen for verbal ones, and elicit concerns. An effective communication involves:

- Using active empathic listening, facilitating responses by the patient;

- Allowing the patient to express any concerns, fears, anxieties, or anger in a manner that aligns with the patient's communication preferences at the time;

- Communicating with an awareness of pitch, rhythm, and silence; it can facilitate a shared understanding and an emotional connection;

- $\quad$ Fostering trust: this is built over time and is stimulated by an understanding of the patient and an appreciation of their point of view.

- Delivering information. ${ }^{(43,47-49)}$

When first communicating with a patient about a particular issue, such as diagnosis or prognosis, it is essential to explore what the patient understands about their illness. Patients should also be asked at the outset how much information they would like and with whom this information should be shared. The best way to ascertain how much information should be discussed is to ask directly - for example: "Would you like to discuss this further, or should we talk about it further once we have more information?". When delivering information, it is important to avoid false reassurance or leaping to a definite diagnosis of cancer without further investigations. Instead, present the information in a clear non-scientific language.

(2) Breaking bad news. Breaking bad news allows for goals of care discussion and patient care consistent with such goals while increasing the quality of life for patients and caregivers. ${ }^{(48,49)}$ What skills and techniques can a physician use when breaking bad news?

- $\quad$ Preparing to deliver bad news. ${ }^{(50,51)}$

Breaking bad news requires additional steps to prepare for this conversation. The S.P.I.K.E.S. protocol is a practical method for breaking bad news at any stage of the disease. ${ }^{(50)}$

- SET UP the interview: arrange in advance that the patient can invite significant others who may be important to attend the meeting. Arrange for privacy and sufficient time, sit down, make a connection with the patient, and avoid interruptions.

- $\quad$ - Assess the patient's PERCEPTION: explore what does the patient knows.

- $\quad$ - Obtain the patient's INVITATION: explore how much does the patient want to know. 
- - Give KNOWLEDGE and information to the patient: warn the patient that bad news is coming, start at the level of comprehension and vocabulary of the patient, use nontechnical words, avoid excessive bluntness, give information in small portions, and check for the patient's understanding.

- $\quad$ - Address the patient's EMOTIONS with empathic responses.

- - SUMMARIZE and STRATEGIZE: Check the patient's understanding and ask if the patient is ready at that time to discuss a plan. If the answer is "yes," make a treatment plan. If not, then give the patient time to reflect and schedule another visit within a short interval.

- $\quad$ Expecting and empathizing with emotions. ${ }^{(52,53)}$ It is crucial for patients and caregivers to feel that the emotional impact of the news is acknowledged. A mnemotechnics that is helpful in this regard is N.U.R.S.E.: name the emotion, understand and respect the emotion, support the patient, and explore the emotion.

- Including patients' preference for information disclosure. ${ }^{(54,55)}$

Requests to withhold bad news about a diagnosis or prognosis may come directly from the patient or from the family. According to the principle of autonomy, the patient should have the right to choose whether or not to be told information about his or her illness. If a family requests nondisclosure, ask about reasons for this request and check with the patient whether it reflects their wishes.

(3) Discussing goals of care and advance care planning. How to approach a goals of care discussion?

- Identifying the goals of care. ${ }^{(56,57)}$

Patients may have a broad spectrum of goals of care depending on the situation, ranging from cure or prolonged life to finding meaning in life, quality of life, symptom control, spending time with loved ones, and dying peacefully with dignity. It is important to identify and acknowledge these goals, since an individual's values will influence how they prioritize goals of care, and two patients with a similar prognosis may desire very different courses of treatment. A clinical pearl of communication when having a goals of care discussion is "hope for the best, prepare for the worst", which acknowledges that hope can be sustained while also planning for the occurrence of clinical situations that may evolve quickly.

- Goals of care may shift over the disease trajectory. ${ }^{(57)}$

Goals of care should be readdressed frequently throughout the patient's disease course and individualized based on the patient's stage of disease and unique characteristics.
Since the prognosis is inextricable from the discussion of goals of care, the latter should be addressed when there is a significant change expected in the patient's care. Terms such as curable, controlled, or terminal disease need to be explained to avoid miscommunication.

- $\quad$ Involving palliative care early. ${ }^{(6,58)}$

Whenever it is available, a palliative care team should be involved early after the diagnosis of incurable cancer to support goals of care and advance care planning discussions.

- $\quad$ Advance directives. ${ }^{(59)}$

Advance directives typically consist of a living will and the assignment of a substitute decision-maker, or durable power of attorney, who will make decisions for a patient in the case of incompetence. They provide an opportunity for patients to state their preferences for care while they are capable of doing so. It is important to emphasize to patients that they should explicitly discuss their treatment preferences with their family members as well as their physicians.

(4) Family meetings. ${ }^{(43,48-50,60,61)}$ How to lead a family meeting?

- $\quad$ Indications for a family meeting. ${ }^{(43,48,49,60)}$

Common indications for a family meeting are a change in status of the patient, a change in the treatment plan, discord among family members, or a plan for discharge home from the hospital.

- Involving family/caregivers in the family meeting. ${ }^{(61)}$

The "family" of the patient includes all those whom the patient identifies as important and may include both relatives and close friends. Permission should be obtained from the patient to discuss the situation and treatment plan with an appointed family member.

- Including key health care members of a family meeting. ${ }^{(43,60)}$

Key members of the health care team should also attend (e.g., primary physician, nurse, social worker). At the same time, it is also important not to overwhelm the family with too many health care professionals.

- $\quad$ Steps of the family meeting. ${ }^{(43,50,60)}$

The meeting should occur in a private setting. If the meeting is occurring in a patient's hospital room, it is courteous to notify others in the room in advance so that they can arrange to be elsewhere for the duration of the meeting, if possible. Steps in conducting the meeting are similar to the S.P.I.K.E.S. steps discussed above:

- Introductions are made, and the meeting leader briefly summarizes the goals of the meeting. 
- The family's understanding of the patient's condition and treatment plan should be clarified. If one family member speaks, it is important to elucidate whether this is the joint understanding of all family members, or whether there are differing points of view among them.

- $\quad$ The meeting leader then summarizes the current situation from the perspective of the treating team, and any potential misunderstandings can be clarified. There may, at this point, be a conflict between points of view. It is essential to listen to these points of view, validate the emotions resulting, and direct the meeting forward towards a treatment plan.

- $\quad$ At the end of the meeting, clear goals for care should be established and summarized.

It is helpful, particularly in large families, to designate a family spokesperson during the meeting so that all future communication with the family can occur through that individual.

(5) Communication in the last hours/days of life..$^{(48,49,62,63)}$ How to approach communication in the last hours/days of life?

- $\quad$ Difference with other forms of communication. $(48,49,63)$

In the last days to hours of life or in the situation of patients who are no longer competent, clinician-family communication becomes critical. It requires awareness of the roles of various family members as well as an appreciation for the vast array of emotions and conflicts that may arise in difficult times.

- $\quad$ Decisions to be made. ${ }^{(48,49,62)}$

Many other decisions need to be made besides the code status or planning for a crisis situation. These include preferences about the extent of investigations, aggressiveness of treatment, hospice enrollment, place of death, organ donation, and religious rites to be performed prior to or after death.

- $\quad$ Addressing health care needs. ${ }^{(48,49,62)}$

- Patient needs. In the last days and hours of life, the patient's desire for information often lessens compared to their need for symptom management and emotional support. It is important to ask the patient to what extent they still want to be involved in decisions, or whether they want to delegate these decisions to another family member. Ultimately, when the patient is no longer competent, the main communication is with the patient's assigned substitute decision maker.

- Caregiver/family needs. The family requires a great deal of communication and information to prepare emotionally and practically for the patient's death. If the patient is imminently dying and the cause is irreversible, it is vital to meet formally with the family to explore any outstanding concerns and emphasize the goals of care.
Poor communication resulting from an intent to protect the patient or family from bad news may have the opposite and negative impact of increasing family conflict.

- $\quad$ Guiding the family during the dying process. $(48,49,62,63)$

The family will need explicit guidance regarding what to expect during the dying process. The clinician should explain that patients will likely stop eating and drinking and that verbal communication will likely cease as sleep increases. The family may feel helpless at this point and take comfort in knowing that they are helping simply with their presence or with small gestures such as assistance with the patient's mouth care or other comfort care.

- Cultural and religious connotations. ${ }^{(64)}$

End-of-life care also involves exploring how a patient's culture, religion, or spiritual belief system affects their end-of-life decision or making or care preferences. The health care team should address and facilitate any cultural or religious ritual related to the death process with the family.

Grief and loss. ${ }^{(65,66)}$

End-of-life conversations that include caregivers or bereaved family members allow dialogue about personal relationships and memories, facilitate planning for the future and enable expressions of essential thoughts and sentiments, including gratitude, love, forgiveness, and farewell. Bereavement care should not be overlooked. Families could be referred to psychosocial supports when considered appropriate and identify any local resources to support families in the bereavement process.

\section{Physical symptoms}

\section{Refractory symptoms}

Refractory severe symptoms are those considered absolutely intolerable by the patient and that cannot be controlled despite all efforts to adopt conducts that do not compromise patient's level of consciousness. They must fulfill one of the criteria below, preferably evaluated by more than one member of the health team:(67-69)

- additional therapeutic interventions will not be able to promote adequate relief;

- $\quad$ the available additional therapeutic interventions are associated with excessive and intolerable (acute or chronic) adverse effects;

- additional therapeutic interventions will not be able to promote relief in an acceptable time frame.

The importance of adequately defining refractoriness of a symptom is essential if subsequent courses of action - especially palliative sedation - are to be adopted in a safe, effective, and ethical manner. 
Inadequate or incomplete assessment of a symptom may lead to unnecessary or early indication for palliative sedation..$^{(70,71)}$

\section{Refractory symptoms evaluation}

In the oncologic setting, the symptoms that most often become refractory are pain, dyspnea, anxiety, and agitated delirium, but any severe symptom can be considered refractory, including spiritual distress. ${ }^{(72)}$

Clinical history and physical examination should be based on a review of the case as a whole, seeking confirmation of irreversible prognosis and potentially reversible conditions causing the symptoms (acute intestinal obstruction, intracranial hypertension, infections, acute urinary retention, inadequate pain management, among others). Additional complementary tests (laboratory, radiological or otherwise) are rarely needed. Such procedures should be restricted to situations where there are still doubts about the reversibility of the symptom, always analyzing the risks and benefits of their results. ${ }^{(73)}$

The review of all strategies instituted for the control of symptoms must be judicious and realized, preferably by a multi professional team trained in palliative care. The review of the instituted treatments is the most important aspect in the definition of refractoriness of a symptom. Its conduction by a multiprofessional team with expertise in palliative care reduces the chances of neglecting potentially beneficial approaches and optimizes symptom control, often culminating in the nonindication of sedation.

The definition of refractoriness of a symptom is up to the physician, but the determination of its intolerability is up to the patient. Thus, the decision to administer palliative sedation should not be made in response to a specific momentary situation, but rather in the context of a palliative care plan, in which physician and patient together define the situations that will justify such a strategy.

\section{Psychological issues}

Anxiety is the first manifest symptom even before the diagnosis in oncology is confirmed. The suspicion of the diagnosis, by itself, makes the patient and his relatives start to elaborate defense mechanisms in relation to the possibility of the disease. The first reaction is to deny the possibility of diagnosis, associated with the magical thought that the exams may be indicating a false diagnosis. ${ }^{(74,75)}$

Anxiety symptoms may be present before any symptoms arising from the disease itself, or any therapeutic intervention. Diagnostic and therapeutic procedures are part of an unknown universe for most patients, and the fear of the unknown generates anguish, a more visceral form of anxiety. ${ }^{(76)}$

After the critical period of shock with the diagnosis and the initial denial reaction, the patient mobilizes his psychic resources in a reaction phase, using psychological defense mechanisms such as repression, denial, minimization, negotiation, rationalization, withdrawal, and moments of self-destructive tendencies.
This emotional reaction in unexpected and fluctuating intensity, which can last from days to weeks, manifests itself out of apathy to affective turbulence, despair, depression, hopelessness, helplessness, hostility, aggression, anger, sadness, and bodily pain. ${ }^{(77)}$

These phases of shock and crisis are followed by a phase of information processing and changes in the usual structure of life. There is a more detailed reflection on the events, a search for solutions and acceptance. ${ }^{(78)}$ There may still be magical thoughts that depart from reality, bargaining behaviors and changes in spiritual beliefs. This elaboration phase can take from weeks to months and is dependent on tolerance to therapeutic interventions, changes in body image or capacity to perform and, of course, on the evolution of the disease. ${ }^{(79)}$

The evolution between these phases is not linear, and there may be cyclical movements, it returns to previous phases, depending on the clinical evolution and the performance of follow-up exams. The processing of this traumatic crisis can lead to a reorientation in life, with acceptance of the facts that have occurred, a new confidence and the acceptance of a new horizon of normality. The challenge for survivors is to deal with the losses and try to establish a new "normal". The consequences of the disease and treatments, changes in body image and functionality (physical, work, social, etc.) determine the degree of difficulty in this adaptation. ${ }^{(80)}$

The clarity of communication throughout this process is essential for the patient to be able to build this new way of life. If the prognosis is not a cure, this process becomes even more relevant so that the patient and his family can make the best decisions in relation to their care plan and guidelines for the end of life. ${ }^{(81)}$

Reactive depressive symptoms are always common, from pre-diagnosis to the final moments of life. They tend to be more persistent and more pronounced for patients with a worse prognosis and worse symptom control. The presence of symptoms of causing discomfort and limitations, inadequately controlled (in all its dimensions), increase suffering and the chances of depression. Symptoms perceived as intense, not adequately resolved, associated with lack of hope, are among the causes of suicide among patients with neoplasms. ${ }^{(82)}$

The amplitude of the depressive symptoms can lead to the diagnosis of depression itself in more than a third of the patients, with the depressive condition persisting even in the remission phase of the disease. (83) The diagnosis of depression requires differential diagnosis with fatigue and endocrine and metabolic changes. ${ }^{(84,85)}$

The evolution of antineoplastic treatment has caused the number of survivors to increase rapidly, making reintegration into social life and work activities an area of great concern now. It is not enough to make the cancer remit, but it is necessary to re-establish the best quality of life and the maximum individual and social functionality. ${ }^{(86)}$ 
Various symptoms are underdiagnosed, underevaluated and inadequately treated in patients with cancer. Many successful treatments cause changes in body image and endocrine changes. Often seen as "the price of a cure", these dysfunctions are seen as "as expected". An important area, in this respect, is the issues related to sexuality and love life. Although concerns about fertility (where relevant) are practically an anomaly of good clinical practice, aspects of sexuality are, for many reasons, left untouched. ${ }^{(87)}$

Of course, it is not always possible to restore the pattern of sexuality that existed before treatments involving genitals, changes in body image and libido. But investigating these problems and bringing them up allows a multidisciplinary team to assist in the construction of a new sexuality, new possibilities of sexual intercourse that, if they do not restore the old pattern, may allow satisfactory practices. ${ }^{(88)}$

Like all symptoms, it is important to recognize its presence, assess it appropriately and treat it appropriately. This goes for all physical symptoms and for psycho- psychological, social, and spiritual dysfunctionalities. ${ }^{(89)}$

\section{Caregiver care (bereavement care)}

Understanding caregivers as a part of the unit of care is primordial in the oncology setting. Frequently, caregivers for cancer patients face long periods of psychological distress overlapping high burden of clinical morbidity neglected at the expense of prioritizing the health of the cancer patients. Caregivers are often partners, friends, relatives who play a central role in providing care, despite health professional input. They are responsible for months or years for complex tasks: from assistance with activities of daily living to managing medical care and assisting with decision making. Being a caregiver may also involve considerable physical, psychological, economic, and domestic challenges. ${ }^{(90)}$ These can take their toll on a caregiver, who also needs to deal with their own sorrow and sense of impending loss. Such caregiver burden, can affect aspects of caregivers' wellbeing and health, resulting in fatigue, sleeping problems, weight loss, depression, anxiety, and an increased risk of death. ${ }^{(91)}$

A recent review paper pointed to some risk factors for adverse mental health outcomes in caregivers: those related to the patient's declining status, symptom distress, and poor prognostic understanding. ${ }^{(92)}$ Among the results from 16 randomized trials, the most promising results for improvement of depression were from early palliative care interventions. Furthermore, are also known risk factors for adverse bereavement outcomes and prolonged grief: unfavorable circumstances of the patient's death, severity of pre-death symptoms, quality of family functioning, level of optimism (especially if low), impact of caregiving duties on caregiver's schedule. ${ }^{(92)}$

Healthcare policies in a number of countries recognize that caregivers of patients in the terminal phase may require a wide range of support, including information about the disease process and personal support. ${ }^{(93)}$
It is important allocate resources to assist caregiver's physical needs such as adequate sleep, domestic help and even financial support, as many of them are forced to quit their jobs. Some strategies previously described to support caregivers are: to reduce the amount of care provided by a caregiver, for example by offering respite services; to improve coping skills, for example by providing programs that facilitate problem solving; to improve wellbeing, for example by providing psychological programs such as counselling, relaxation techniques and psychotherapy; and to deliver such interventions at an appropriate time ('considering window of opportunity'). ${ }^{(90)}$

Regarding terminal care, evidence from the literature reinforces the need for palliative care services to take action during the pre-bereavement period to assess and support family caregivers. Ideally the bereavement team should be involved in the care of the family before the death, as an opportunity to assist and prepare family and friends and identify those who may be at higher risk for distress post-bereavement. (94) However, comprehensive palliative care for the patient's family and caregivers should continue after the patient's death. Besides ensuring a peaceful death, immediate issues that should be observed as offering condolences, a culturally sensitive treatment of the body, providing family time with the body and involving chaplain or other spiritual leaders to assess the family's desire for religious ritual or spiritual support. ${ }^{(95)}$ Generally, the bereavement support is best provided by the hospice team or by skilled mental health care professionals. The family may request a debriefing meeting with the medical team and, if possible, it might be helpful. Moreover, a well-supported end-of-life care experience will facilitate the family's acceptance of appropriate referrals for cancer risk assessment. ${ }^{(96)}$

\section{Spiritual care}

According to the World Health Organization (WHO), palliative care is concerned with the physical, psychosocial, and spiritual problems of patients with life-threatening illnesses and of their families. ${ }^{(97)}$ The management of spiritual needs is almost always a great challenge due to the inadequate preparation of health professionals in meeting spiritual demands, the lack of time to dedicate themselves to these aspects, and the rarity of the availability of professionals in this area to monitor the patient. ${ }^{(98)}$

The identification and assessment of the spiritual dimensions of the disease are essential skills for nurses and doctors in palliative care. It is often necessary to offer this assistance as part of their care and to explore the comfort perceived by the patient when discussing spiritual and religious issues. ${ }^{(99)}$

In the absence of a chaplaincy professional, part of the demands ends up being met by psychology professionals. ${ }^{(100)}$ When they do not feel qualified, the search for a professional external to the institution may be the most reasonable alternative. It is important, however, that this spiritual (or possibly religious) assistance is in line with the discourse and performance of the team that assists the patient. 
Spirituality is often a relevant issue in a palliative context, yet there is a need to differentiate spirituality from religion. Spirituality is one of the fundamental dimensions of quality of life and culture care, ${ }^{(101)}$ and may be defined as a journey of self-discovery, which allows a person to experience the transcendent meaning in life, expressed as a search for the sacred (God, nature, family, etc.), whatever gives a person a sense of meaning and purpose of life. (102)

Evidence base demonstrates that spirituality frequently plays a central and complex role in patients' and families' experiences of incurable illness, including influencing quality of life, and medical decision-making, ${ }^{(103)}$ but in the context of an increasingly spiritually diverse population, spirituality can be perceived as a nebulous subject for healthcare professionals.

For those patients who express a strong spiritual connection or sense of 'something greater' or 'a higher power', encouraging the exploration of those feelings and beliefs through chaplains, clergypersons, or members of the interdisciplinary palliative care team can help provide context, meaning and purpose in their lives impacted by serious illness. One of the goals of effective palliative care is the facilitation of personal growth and psychological resilience in dealing with one's health challenges. ${ }^{(104)}$

Integrative medicine provides a set of tools and philosophies intended to enhance wellness and a sense of wellbeing and many of these modalities may be useful in reducing symptoms commonly experienced by patients receiving palliative care and may offers nonverbal, noncognitive avenues for many to achieve a peaceful and calm inner state. Some integrative approaches facilitate patients attaining greater self-awareness and may meet their spiritual needs without the religious overtones that accompany traditional prayer. ${ }^{(105)}$

\section{Practical ethical challenges till the last days of life}

Respect for autonomy is a key principle in contemporary medical ethics. ${ }^{(106)}$ Empirical studies show that decision-making, exclusively focused on the individual exercise of autonomy fails to align well with patients' preferences at the end of life. The need for a more contextualized approach that meets real-life complexities experienced in end-of-life practices has been repeatedly advocated.(107)

The notion of 'relational autonomy' may be a suitable alternative approach. Relational autonomy has even been advanced as a foundational notion of palliative care, shared decision-making, and advance-care planning. ${ }^{(107)}$

The applied-ethics approach of principlism lends itself well to translation into ethicolegal standards, such as informed consent. Implementation of informed consent as a tool to express patients' autonomy is considered indeed to be a major outcome of contemporary bioethics.
More specifically than the consent form, in Brazil, the Federal Council of Medicine established the "advance guidelines of will", a term by which the patient can determine his representative and specify his wishes in the limitation in relation to the therapeutic procedures to be performed. ${ }^{(108)}$

The advance directives of will are defined as the set of wishes, previously and expressly manifested by the patient, about care and treatments that they want, or not, to receive when they are unable to express, freely and autonomously, his will. $\left(\right.$ Art. $\left.1^{\circ}\right) .{ }^{(108)}$

In lucid and communicative patients, therapeutic proposals should be discussed promptly, based on good communication. However, in decisions about the care and treatment of patients at times when they are unable to communicate, or to express their will freely and independently, the doctor will consider their anticipated directives of will (Art. $2^{\circ}$ ), theoretically established at the moment the patient was in full enjoyment of his mental abilities). ${ }^{(108)}$

It is up to the patient to designate a representative to make the decisions in case the patient is unable to do so. In this case, the representative's decisions will be considered by the doctor. The representative is determined by the patient, regardless of kinship relationships (Art. $\left.2^{\circ}, \S 1^{\circ}\right) .^{(108)}$

The directives do not absolutely establish medical conduct. The doctor will no longer take into consideration the advance directives of the patient or representative who, in his analysis, are in disagreement with the precepts dictated by the Medical Code of Ethics, or with the good practice of medicine, and it is not possible for the patient or his representative determines conduct considered futile or harmful (Art. $\left.2^{\circ}, \S 1^{\circ}\right) .^{(108)}$

The Medical Code of Ethics, in its fundamental assumptions, establishes that the physician will exercise his profession with autonomy, not being obliged to provide services that contradict the dictates of his conscience or to those who do not wish to, except in situations of absence of another doctor, in case of urgency or emergency, or when your refusal may damage the patient's health. And that, in the professional decision-making process, in accordance with the dictates of their conscience, the doctor will accept the choices of their patients regarding the diagnostic and therapeutic procedures expressed by them, if they are appropriate to the case and scientifically recognized. In irreversible and terminal clinical situations, the doctor will avoid carrying out unnecessary diagnostic and therapeutic procedures and provide the patients under his care with all appropriate palliative care. ${ }^{(109)}$

The Medical Code of Ethics establishes that the physician is prohibited from exaggerating the severity of the diagnosis or prognosis, complicating therapy, or exceeding the number of visits, consultations or any other medical procedures (Art. 35). ${ }^{(109)}$ 
The Conselho Federal de Medicina (CFM) resolution establishes that the patient's advance directives will prevail over any other nonmedical opinion, including the wishes of family members $\left(\S 3^{\circ}\right)$, and that, for legal purposes, it will be enough for the doctor to register the advance directives of will that directly communicated to them by the patient $\left(\$ 4^{\circ}\right) .{ }^{[108]}$

If the patient's advance directives are not known, nor if there is a designated representative, available family members or lack of consensus between them, the doctor will appeal to the institution's bioethics committee, if any, or, failing this, to the Ethics Committee Hospital doctor or the Regional and Federal Medical Council to base its decision on ethical conflicts, when it understands this necessary and convenient measure $\left(\S 5^{\circ}\right) .^{(108)}$

When what the patient wants is less intervention than medicine can offer, the limit of the patient's desire must be respected. The two main problems are when the patient wants more than what appears to be scientifically justified, or when the doctor offers the patient therapeutic measures where the benefit borders on futility.

Establishing the boundaries between the usefulness and futility of treatments, that is, the magnitude of their benefits, has been hard work by several specialist societies.

\section{Overcoming barriers to providing quality of end-of- life care}

Although much has been publicized in Brazil regarding palliative care as an essential tool for ensuring comfort and dignity at the end-of-life, our country still has a great challenge ahead. According to the death quality index, published in 2015 by "The Economist Intelligence Unit", ${ }^{(110)}$ Brazil emerges in the $42^{\text {nd }}$ position in the ranking of quality of death among 80 countries evaluated in the world. Even among American countries, we occupy the $10^{\text {th }}$ position among the 17 evaluated. These results are a direct reflection of the barriers we encounter to offer palliative care to our patients in their final stages of life, including the oncological scenario.

Challenges such as insufficient public policies, a limited number of palliative care services (and the concentration of these services in certain regions to the detriment of others) and lack of financial investment in end-of-life care could be cited as contributing to the inadequate support for our patients.

Although insufficient, there are milestones, which were not brought. For example, the two main national policies on the subject are missing, namely:

Resolution No. 41, of October 31, 2018, from the tripartite intermanagement commission, Ministry of Health, National Council of Health Secretaries and National Council of Municipal Health Secretariats, which provides for guidelines for the organization of palliative care, in the light of integrated continuous care, within the scope of the Unified Health System (SUS).
This is the most robust national document that exists on the organization of palliative care in the country. Along with the CFM documents, this document supports any discussion of palliative care in our country.

The Department of Specialized Health Care/ Ministry of Health (SAES/MS) No. 1399, of December 17, 2019, redefines the criteria and referential parameters for enabling health facilities in high complexity oncology within the SUS. On page 14 of this ordinance, there are parameters that, since 2019 , are understood as the minimum quality standard in palliative care for an institution specializing in oncology in the SUS.

These points are organizational parameters, agreed upon by the main institutions that make up the SUS and that act in the national cancer policy, which in addition to being aligned with points brought in the manuscript and being useful for managers and health professionals. Although insufficient, they are milestones, and I think it would make the article more objective and constructive.

Access to specialized palliative care was surveyed by the National Academy of Palliative Care in an Atlas, listing the 291 teams of specialized palliative care and their distribution in the country. These data draw attention to low number of teams in relation to the size of the population, distributed very unevenly across the country. It is of fundamental importance to develop general palliative care so that palliative care needs can be met. Some national articles addressed this issue of national demand more objectively. ${ }^{(111)}$

However, the most decisive factor is probably related to the gaps in the training of our healthcare professionals in palliative care, including clinical oncologists. Such gaps result not only in poorly qualified care, but also in the spread of prejudices among professionals, patients and family members. Specific training in palliative care is not yet available in most oncology residences, and there is little offer of quality specialization and postgraduate courses. A recent survey characterized that there are 14 CP residences in Brazil. (112)

Contrary to what many people imagine, quality palliative care can be offered by the oncologist himself in the early stage of advanced disease. This is what we can call primary palliative care, for which there is no need to master invasive pain control techniques, or to have expertise in complex procedures such as palliative sedation or palliative extubation, or to have training in spiritual or psychosocial support. This is not what is expected of the clinical oncologist. According to Dr. Jennifer Cheng (2013), ${ }^{(113)}$ of the Johns Hopkins Medical Institutions, offering primary palliative care involves using the practices established in palliative care as part of the oncologists' real routine by prioritizing three essential pillars: polishing the communication techniques, inserting into the common anamnesis the assessment of other common symptoms (in addition to pain) in cancer patients and apply the basic strategies of palliative care to control the most common symptoms. 
Although we are talking about adopting the view of palliative care in the earliest stages of advanced cancer, the training of oncologists in these practices will have a direct impact on improving the quality of care at the end of life. ${ }^{(114)}$ The first positive impact comes from improved communication in relation to the prognosis, which favors the sharing of decisions with the patient and family and the adoption of more sensible and proportionate therapeutic strategies. In addition, adequate communication allows the construction of anticipated directives of will over months to years, making them more assertive and sensible. This facilitates their adoption at the end of life, increasing the quality of care. The second point concerns the increase of the oncologist's understanding of the role of the multiprofessional team, favoring the early performance of psychologists, nurses, chaplains, social workers and other professionals in care, which results in a more comprehensive reception of patients and family members during the phase end-of-life. In addition, oncologists themselves involved in palliative care tend to feel more satisfied with the profession, see more meaning at work and have lower burnout rates. ${ }^{(115)}$

\section{REFERENCES}

1. Hui D, Santos R, Reedy D, Nascimento MSA, Zhukovsky $D S$, Paiva CE, et al. Acute symptomatic complications among patients with advanced cancer admitted to acute palliative care units: a prospective observational study. Palliat Med. 2015 Oct;29(9):826-33. DOI: https:// doi.org/10.1177/0269216315583031

2. Bruera E, Hui D. Integrating supportive and palliative care in the trajectory of cancer: establishing goals and models of care. J Clin Oncol. 2010;28(25):4013-7. DOI: https://doi.org/10.1200/JCO.2010.29.5618

3. World Health Organization (WHO). Definition of palliative care. Geneva: WHO; 2019.

4. Hui D, Hannon BL, Zimmermann C, Bruera E. Improving patient and caregiver outcomes in oncology: team-based, timely, and targeted palliative care. Cancer J Clin. 2018 Sep;68(5):356-76. DOI: https:// doi.org/10.3322/caac.21490

5. Temel JS, Jackson VA, Billings JA, Dahlin C, Block SD, Ostler BP, et al. Phase II study: Integrated palliative care in newly diagnosed advanced non-small-cell lung cancer patients. J Clin Oncol. 2007;25(17):237782. DOI: https://doi.org/10.1200/JCO.2006.09.2627

6. Zimmermann C, Swami N, Krzyzanowska M, Hannon B, Leighl N, Oza A, et al. Early palliative care for patients with advanced cancer: a cluster-randomised controlled trial. Lancet. 2014 May;383(9930):1721-30. DOI: https://doi.org/10.1016/S0140-6736(13)62416-2

7. Gaertner J, Siemens W, Meepohl JJ, Antes G, Meffert C, Xander C, et al. Effect of specialist palliative care services on quality of life in adults with advanced incurable illness in hospital, hospice, or community settings: systematic review and meta-analysis. BMJ. 2017 Jun;357:j2925. DOI: https://doi.org/10.1136/ bmj.j2925
8. Kavalieratos D, Corbelli J, Zhang D, Dionne-Odom JN, Ernecoff NC, Hanmer J, et al. Association between palliative care and patient and caregiver outcomes: a systematic review and meta-analysis. JAMA. 2016 Nov;316(20):210414. DOI: https://doi.org/10.1001/jama.2016.16840

9. Haun MW, Estel S, Rücker G, Friedrich HC, Villalobos M, Thomas M, et al. Early palliative care for adults with advanced cancer. Cochrane Database Syst Rev. 2017 Jun;6(6):CD011129.

10. Hui D, Bruera E. Models of palliative care delivery for patients with cancer. J Clin Oncol. 2020;38(9):852-65. DOI: https://doi.org/10.1200/JCO.18.02123

11. Bickel KE, McNiff K, Buss MK, Kamal A, Lupu D, Abernethy $A P$, et al. Defining high-quality palliative care in oncology practice: an American Society of Clinical Oncology/ American Academy of Hospice and Palliative Medicine guidance statement. J Oncol Pract. 2016;12(9):e828-e38. DOI: https://doi.org/10.1200/JOP.2016.010686

12. Hui D, Paiva CE, Del Fabbro E, Steer C, Naberhuis J, Van de Wetering $M$, et al. Prognostication in advanced cancer: update and directions for future research. Support Care Cancer. 2019 Mar;27(6):1973-84. DOI: https://doi.org/10.1007/s00520-019-04727-y

13. Hui D, Li MO, Paiva CE. The importance of prognostication: impact of prognostic predictions, disclosures, awareness, and acceptance on patient outcomes. Curr Treat Options Oncol. 2021 Jan;22(2):1-14. DOI: https://doi.org/10.1007/s11864-020-00810-3

14. Weeks JC, Cook F, O'Day SJ, Peterson LM, Wenger $\mathrm{N}$, Reding $\mathrm{D}$, et al. Relationship between cancer patients' predictions of prognosis and their treatment preferences. JAMA. 1998 Jun;279(21):1709-14. DOI: https://doi.org/10.1001/jama.279.21.1709

15. Sborov K, Giaretta S, Koong A, Aggarwal S, Aslakson $\mathrm{R}$, Gensheimer MF, et al. Impact of accuracy of survival predictions on quality of end-of-life care among patients with metastatic cancer who receive radiation therapy. J Oncol Pract. 2019;15(3):e262-e70. DOI: https://doi.org/10.1200/JOP.18.00516

16. Hui D. Prognostication of survival in patients with advanced cancer: predicting the unpredictable? Cancer Control. 2015 Oct;22(4):489-97. DOI: https://doi. org/10.1177/107327481502200415

17. Reid VL, McDonald R, Nwosu AC, Mason SR, Probert SR, Ellershaw JE, et al. A systematically structured review of biomarkers of dying in cancer patients in the last months of life; an exploration of the biology of dying. PLoS One. 2017 Apr;12(4):e0175123. DOI: https://doi.org/10.1371/journal.pone.0175123

18. Morita T, Tsunoda J, Inoue S, Chihara S. The palliative prognostic index: a scoring system for survival prediction of terminally ill cancer patients. Support Care Cancer. 1999 Apr;7(3):128-33. DOI: https://doi. org/10.1007/s005200050242

19. Maltoni M, Nanni O, Pirovano M, Scarpi E, Indelli M, Martini C, et al. Successful validation of the palliative prognostic score in terminally ill cancer patients. J Pain Symptom Manag. 1999 Apr;17(4):240-7. DOI: https:// doi.org/10.1016/S0885-3924(98)00146-8 
20. Hui D, Park M, Liu D, Paiva CE, Suh SY, Morita T, et al. Clinician prediction of survival versus the palliative prognostic score: which approach is more accurate? Eur J Cancer. 2016 Sep;64:89-95. DOI: https://doi. org/10.1016/j.ejca.2016.05.009

21. Hui D, Ross J, Park M, Dev R, Vidal M, Liu D, et al. Predicting survival in patients with advanced cancer in the last weeks of life: How accurate are prognostic models compared to clinicians' estimates? Palliative Med. 2020 Jan;34(1):126-33.

22. Hui D, Maxwell JP, Paiva CE. Dealing with prognostic uncertainty: the role of prognostic models and websites for patients with advanced cancer. Curr Opin Support Palliat Care. 2019 Dec;13(4):360-8. DOI: https://doi.org/10.1097/SPC.0000000000000459

23. Avati A, Jung K, Harman S, Downing L, Ng A, Shah NH. Improving palliative care with deep learning. BMC Medical Inform Decis Mak. 2018;18(4):55-64. DOI: https://doi.org/10.1186/s12911-018-0677-8

24. Morita T, Ichiki T, Tsunoda J, Inoue S, Chihara S. A prospective study on the dying process in terminally ill cancer patients. Am J Hosp Palliat Med. 1998 Jul;15(4):217-22. DOI: https://doi. org/10.1177/104990919801500407

25. Kehl KA, Kowalkowski JA. A systematic review of the prevalence of signs of impending death and symptoms in the last 2 weeks of life. Am J Hosp Palliat Med. 2013;30(6):601-16. DOI: https://doi. org/10.1177/1049909112468222

26. Hui D, Santos R, Chisholm G, Bansal S, Silva TB, Kilgore $\mathrm{K}$, et al. Clinical signs of impending death in cancer patients. Oncologist. 2014 Apr;19(6):681-7. DOI: https://doi.org/10.1634/theoncologist.2013-0457

27. Hui D, Santos R, Chisholm G, Bansal S, Crovador CS, Bruera E. Bedside clinical signs associated with impending death in patients with advanced cancer: preliminary findings of a prospective, longitudinal cohort study. Cancer. 2015;121(6):960-7. DOI: https:// doi.org/10.1002/cncr.29048

28. Hui D, Hess K, Santos R, Chisholm G, Bruera E. A diagnostic model for impending death in cancer patients: preliminary report. Cancer. 2015 Jul;121(21):3914-21. DOI: https://doi.org/10.1002/cncr.29602

29. Earle CC, Park ER, Lai B, Weeks JC, Ayanian JZ, Block $S$, et al. Identifying potential indicators of the quality of end-of-life cancer care from administrative data. J Clin Oncol. 2003;21(6):1133-8. DOI: https:// doi.org/10.1200/JCO.2003.03.059

30. Cherny NI, Catane R, Kosmidis P, Members of the ESMO Taskforce on Supportive and Palliative Care. ESMO takes a stand on supportive and palliative care. Ann Oncol. 2003 Sep;14(9):1335-7. DOI: https://doi. org/10.1093/annonc/mdg379

31. Peppercorn JM, Smith TJ, Helft PR, DeBono DJ, Berry SR, Wollins DS, et al. American society of clinical oncology statement: toward individualized care for patients with advanced cancer. J Clin Oncol. 2011;29(6):75560. DOI: https://doi.org/10.1200/JCO.2010.33.1744
32. Earle CC, Neville BA, Landrum MB, Ayanian JZ, Block SD, Weeks JC, et al. Trends in the aggressiveness of cancer care near the end of life. J Clin Oncol. 2004;22(2):31521. DOI: https://doi.org/10.1200/JCO.2004.08.136

33. Zdenkowski N, Cavenagh J, Ku YC, Bisquera A, Bonaventura A. Administration of chemotherapy with palliative intent in the last 30 days of life: the balance between palliation and chemotherapy. Intern Med J. 2013 Jul;43(11):1191-8. DOl: https://doi.org/10.1111/imj.12245

34. Levy CR, Ely W, Kate P, Ruth EA, Donald PL, Randall CJ. Quality of dying and death in two medical ICUs: perceptions of family and clinicians. Chest. 2005 May;127(5):1775-83. DOI: https://doi.org/10.1378/ chest.127.5.1775

35. Luhm MV. Factors influencing oncologists' use of chemotherapy in patients at the end of life: a qualitative study [thesis]. Michigan: University of Michigan Library; 2011.

36. Behl D, Jatoi A. What do oncologists say about chemotherapy at the very end of life? Results from a semiqualitative survey. J Palliat Med. 2010 Jul;13(7):831-5. DOI: https://doi.org/10.1089/jpm.2009.0414

37. Clarke G, Johnston S, Corrie P, Kuhn I, Barclay S. Withdrawal of anticancer therapy in advanced disease: a systematic literature review. BMC Cancer. 2015 Nov;15(1):1-9. DOI: https://doi.org/10.1186/ s12885-015-1862-0

38. Elkin EB, Kim SHM, Casper ES, Kissane DW, Schrag D. Desire for information and involvement in treatment decisions: elderly cancer patients' preferences and their physicians' perceptions. J Clin Oncol, 2007;25(33):5275-80. DOl: https://doi.org/10.1200/ JCO.2007.11.1922

39. White DB, Braddock CH, Bereknyei S, Curtis JR. Toward shared decision making at the end of life in intensive care units: opportunities for improvement. Arch Intern Med. 2007 Mar;167(5):461-7. DOI: https:// doi.org/10.1001/archinte.167.5.461

40. Thompson BT, Cox PN, Antonelli M, Carlet JM, Cassell J, Hill NS, et al. Challenges in end-of-life care in the ICU: statement of the 5th International Consensus Conference in Critical Care: Brussels, Belgium, April 2003: executive summary. Crit Care Med. 2004 Aug;32(8):1781-4. DOI: https://doi.org/10.1097/01. CCM.0000126895.66850.14

41. Buiting HM, Rurup ML, Wijsbek H, Van Zuylen L. Understanding provision of chemotherapy to patients with end stage cancer: qualitative interview study. BMJ. 2011 Apr;342:d1933. DOI: https://doi.org/10.1136/bmj.d1933

42. Schulman-Green DJ, Naik AD, Bradley EH, McCorkle $\mathrm{R}$, Bogardus ST. Goal setting as a shared decision making strategy among clinicians and their older patients. Patient Educ Couns. 2006 Oct;63(1-2):14551. DOI: https://doi.org/10.1016/j.pec.2005.09.010

43. Gilligan T, Coyle N, Frankel RM, Berry DL, Bohlke K, Epstein RM, et al. Patient-clinician communication: American Society of Clinical Oncology Consensus Guideline. J Clin Oncol. 2017;35(31):3618-32. DOI: https://doi.org/10.1200/JCO.2017.75.2311 
44. Cain CL, Surbone A, Elk R, Kagawa-Singer M. Culture and palliative care: preferences, communication, meaning, and mutual decision making. J Pain Symptom Manag. 2018 May;55(5):1408-19. DOI: https:// doi.org/10.1016/j.jpainsymman.2018.01.007

45. Weston WW, Brown JB, Stewart MA. Patient-centred interviewing part I: understanding patients' experiences. Can Fam Physician. 1989 Jan;35:147-51.

46. Brooks LA, Manias E, Bloomer MJ. Culturally sensitive communication in healthcare: a concept analysis. Collegian. 2019 Jun;26(3):383-91. DOI: https://doi. org/10.1016/j.colegn.2018.09.007

47. Rodin G, Zimmermann C, Mayer C, Howell D, Katz M, Sussman J, et al. Clinician-patient communication: evidence-based recommendations to guide practice in cancer. Curr Oncol. 2009 Dec;16(6):42-9. DOI: https:// doi.org/10.3747/co.v16i6.432

48. Correa R, Ridley J, Zimmermann C. Communication in advanced illness. In: Oneschuk D, Hagen N, MacDonald N, eds. Palliative medicine. $3^{\text {rd }}$ ed. Oxford: Oxford University Press; 2012. DOI: https://doi.org/10.1093/ acprof:oso/9780199694143.003.0010

49. Cassie A, Zimmermann C. Structure and process: Communication. In: McKean S, Brotman D, Dressler D, Ginsberg J, Ross J, eds. The principles and practice of hospital medicine. $2^{\text {nd }}$ ed. Boston: McGraw-Hill; 2017.

50. Baile WF, Buckman R, Lenzi R, Glober G, Beale EA, Kudelka AP. SPIKES-a six-step protocol for delivering bad news: application to the patient with cancer. Oncologist. 2000 Aug;5(4):302-11. DOI: https://doi. org/10.1634/theoncologist.5-4-302

51. Von Blanckenburg P, Hofmann M, Rief W, Seifart U, Seifart C. Assessing patients' preferences for breaking Bad News according to the SPIKES-Protocol: the MABBAN scale. Patient Educ Couns. 2020 Aug;103(8):16239. DOI: https://doi.org/10.1016/j.pec.2020.02.036

52. Cameron RA, Mazer BL, DeLuca JM, Mohile SG, Epstein RM. In search of compassion: a new taxonomy of compassionate physician behaviours. Health Expect. 2013 Dec;18(5):1672-85. DOI: https://doi.org/10.1111/ hex. 12160

53. Smith RC, Hoppe RB. The patient's story: integrating the patient-and physician-centered approaches to interviewing. Ann Intern Med. 1991 Sep;115(6):470-7. DOI: https://doi.org/10.7326/0003-4819-115-6-470

54. Houska A, Loučka M. Patients' autonomy at the end of life: a critical review. J Pain Symptom Manag. 2019 Apr;57(4):835-45. DOI: https://doi.org/10.1016/j. jpainsymman.2018.12.339

55. Uchida M, Sugie C, Yoshimura M, Suzuki E, Shibamoto $Y$, Hiraoka $M$, et al. Factors associated with a preference for disclosure of life expectancy information from physicians: a cross-sectional survey of cancer patients undergoing radiation therapy. Support Care Cancer. 2019 Mar;27(12):4487-95. DOI: https://doi. org/10.1007/s00520-019-04716-1
56. Bernacki RE, Block SD. Communication about serious illness care goals: a review and synthesis of best practices. JAMA Intern Med. 2014 Dec;174(12):19942003. DOI: https://doi.org/10.1001/jamainternmed.2014.5271

57. Berntsen GKR, Gammon D, Steinsbekk A, Salamonsen A, Foss N, Ruland C, et al. How do we deal with multiple goals for care within an individual patient trajectory? A document content analysis of health service research papers on goals for care. BMJ Open. 2015;5(12):e009403. DOI: https://doi.org/10.1136/ bmjopen-2015-009403

58. Temel JS, Greer JA, El-Jawahri A, Pirl WF, Park ER, Jackson VA, et al. Effects of early integrated palliative care in patients with lung and GI cancer: a randomized clinical trial. J Clin Oncol. 2017;35(8):834. DOI: https:// doi.org/10.1200/JCO.2016.70.5046

59. Dadalto L, Tupinambás U, Greco DB. Advanced directive: a Brazilian model. Rev Bioét. 2013 Dec;21(3):463-76. DOI: https://doi.org/10.1590/S198380422013000300011

60. Hudson P, Quinn K, O'Hanlon B, Aranda S. Family meetings in palliative care: multidisciplinary clinical practice guidelines. BMC Palliat Care. 2008 Aug;7(1):112. DOI: https://doi.org/10.1186/1472-684X-7-12

61. Sanderson CR, Cahill PJ, Philips JL, Johnson A, Lobb EA. Patient-centered family meetings in palliative care: a quality improvement project to explore a new model of family meetings with patients and families at the end of life. Ann Palliat Med. 2017;6(Suppl 2):S195-S205. DOI: https://doi.org/10.21037/apm.2017.08.11

62. Chapman L, Ellershaw J. Care in the last hours and days of life. Medicine. 2020 Jan;48(1):52-6. DOI: https:// doi.org/10.1016/j.mpmed.2019.10.006

63. Anderson RJ, Bloch S, Armstrong M, Stone PC, Low JTS. Communication between healthcare professionals and relatives of patients approaching the endof-life: a systematic review of qualitative evidence. Palliat Med. 2019 Jun;33(8):926-41. DOI: https://doi. org/10.1177/0269216319852007

64. Pereira-Salgado A, Mader P, O'Callaghan C, Boyd L, Staples M. Religious leaders' perceptions of advance care planning: a secondary analysis of interviews with Buddhist, Christian, Hindu, Islamic, Jewish, Sikh and Bahá'í leaders. BMC Palliat Care. 2017 Dec;16(1):110. DOI: https://doi.org/10.1186/s12904-017-0239-3

65. Lichtenthal WG, Roberts KE, Catarozoli C, Schofield E, Holland JM, Fogarty JJ, et al. Regret and unfinished business in parents bereaved by cancer: a mixed methods study. Palliat Med. 2020 Feb;34(3):367-77. DOI: https://doi.org/10.1177/0269216319900301

66. Patterson P, McDonald FEJ, Kelly-Dalgety E, Lavorgna B, Jones $\mathrm{BL}$, Sidis $\mathrm{AE}$, et al. Development and evaluation of the Good Grief program for young people bereaved by familial cancer. BMC Palliat Care. 2021 Apr;20(1):115. DOI: https://doi.org/10.1186/s12904-021-00752-z 
67. Cowan JD, Palmer TW. Practical guide to palliative sedation. Curr Oncol Rep. 2002 Jun;3(3):242-9. DOI: https://doi.org/10.1007/s11912-002-0022-2

68. Chater S, Viola R, Paterson J, Jarvis V. Sedation for intractable distress in the dying-a survey of experts. Palliat Med. 1998 Jun;12(4):255-69. DOI: https://doi. org/10.1191/026921698671831786

69. Cherny NI, Portenoy RK. Sedation in the management of refractory symptoms: guidelines for evaluation and treatment. J Palliat Care. 1994 Jun;10(2):31-8. DOI: https://doi.org/10.1177/082585979401000207

70. Braun TC, Hagen NA, Clark T. Development of a clinical practice guideline for palliative sedation. J Palliat Care. 2004 Jun;6(3):345-50. DOI: https://doi. org/10.1089/109662103322144655

71. Rousseau PC. Palliative sedation. Am J Hosp Palliat Med. 2002 Sep;19(5):295-7. DOI: https://doi. org/10.1177/104990910201900501

72. Teunissen SCCM, Wesker W, Kruitwagen C, Haes HCJM, Voest EE, Graeef A. Symptom prevalence in patients with incurable cancer: a systematic review. J Pain Symptom Manag. 2007 Jul;34(1):94-104. DOI: https://doi.org/10.1016/j.jpainsymman.2006.10.015

73. Coradazzi AL. Diretivas antecipadas de vontade: bem mais que uma lista de desejos finais 2018. Slow Medicine [Internet]. 2018; [access in 2022 Jan 27]. Available from: https://www.slowmedicine.com.br/diretivas-antecipadas-de-vontade-bem-mais-que-uma-lista-de-desejos-finais/

74. Zwingmann J, Vaile WF, Schmier JW, Bernhard J, Keller M. Effects of patient-centered communication on anxiety, negative affect, and trust in the physician in delivering a cancer diagnosis: a randomized, experimental study. Cancer. 2017 Apr;123(16):3167-75. DOI: https://doi.org/10.1002/cncr.30694

75. Pitman A, Suleman S, Hyde N, Hodgkiss A. Depression and anxiety in patients with cancer. BMJ. 2018 Apr;361:k1415. DOI: https://doi.org/10.1136/bmj.k1415

76. Kushner R. Coping with breast cancer: what health professionals can do to help. Breast Cancer. 2021;21-33.

77. Cordova MJ, Riba MB, Spiegel D. Post-traumatic stress disorder and cancer. Lancet Psychiatr. 2017 Apr;4(4):3308. DOI: https://doi.org/10.1016/S2215-0366(17)30014-7

78. Hellstadius Y, Malmström M, Lagergren P, Sundbom M, Wikman A. Reflecting a crisis reaction: Narratives from patients with oesophageal cancer about the first 6 months after diagnosis and surgery. Nurs Open. 2019 Aug;6(4):1471-80. DOI: https://doi.org/10.1002/ nop2.348

79. Harmon J. Tell cancer to take a hike: post traumatic growth on the trail to recovery. Leisure/Loisir. 2019 Jan;44(4):459-78. DOI: https://doi.org/10.1080/1492 7713.2019.1697349

80. Leong-Abdullah MFI, Hami R, Appalanaido GK, Azman $\mathrm{N}$, Shariff NM, Sharif SS. Diagnosis of cancer is not a death sentence: Examining posttraumatic growth and its associated factors in cancer patients. J Psychosocial Oncol. 2019 Mar;37(5):636-51. DOI: https://doi.org/ 10.1080/07347332.2019.1574946
81. McDonald JC, Manoir JM, Kevork N, Le LW, Zimmermann C. Advance directives in patients with advanced cancer receiving active treatment: attitudes, prevalence, and barriers. Support Care Cancer. 2017;25(2):52331. DOI: https://doi.org/10.1007/s00520-016-3433-6

82. Henson KE, Brock R, Charnock J, Wickramasinghe B, Will $\mathrm{O}$, Pitman A, et al. Risk of suicide after cancer diagnosis in England. JAMA Psychiatr. 2019 Jan;76(1):51-60. DOI: https://doi.org/10.1001/jamapsychiatry.2018.3181

83. Tsaras K, Papathanasiou IV, Mitsi D, Veneti A, Keleso M, Zyga S, et al. Assessment of depression and anxiety in breast cancer patients: prevalence and associated factors. Asian Pac J Cancer Prev. 2018;19(6):1661. DOI: https://doi.org/10.22034/APJCP.2018.19.6.1661

84. Kuhnt S, Friedrich M, Schulte T, Cella D, Hinz A. Screening properties of the diagnostic criteria for cancer-related fatigue. Oncol Res Treat. 2019;42(9):440-7. DOI: https://doi.org/10.1159/000501128

85. Jean CY, Syrjala KL. Anxiety and depression in cancer survivors. Med Clin. 2017 Nov; 101(6):1099-113. DOI: https://doi.org/10.1016/j.mcna.2017.06.0

86. McCanney J, Winckworth-Preksnar K, Schatz AA, Nardi EA, Dwyer AJ, Lieu C, et al. Addressing survivorship in cancer care. J Natl Compr Cancer Netw. 2018 Jul;16(7):801-6. DOI: https://doi.org/10.6004/jnccn.2018.7054

87. Flink DM, Kondapalli LA, Kellar-Guenther Y. Priorities in fertility decisions for reproductive-aged cancer patients: fertility attitudes and cancer treatment study. J Adolesc Young Adult Oncol. 2017 Feb;6(3):435-43. DOI: https://doi.org/10.1089/jayao.2016.0072

88. Albers LF, Van Belzen MA, Van Batenburg C, Engelen V, Putter $\mathrm{V}$, Pelger RCM, et al. Discussing sexuality in cancer care: towards personalized information for cancer patients and survivors. Support Care Cancer. 2020 Jan;28(9):422733. DOI: https://doi.org/10.1007/s00520-019-05257-3

89. Shapiro CL. Cancer survivorship. N Engl J Med. 2018 Dec;379(25):2438-50. DOI: https://doi.org/10.1056/NEJMra1712502

90. Candy B, Jones L, Drake R, Laurent B, King M. Interventions for supporting informal caregivers of patients in the terminal phase of a disease. Cochrane Database Syst Rev. 2011;6:CD007617. DOI: https:// doi.org/10.1002/14651858.CD007617.pub2

91. Thomas C, Morris SM, Harman JC. Companions through cancer: the care given by informal carers in cancer contexts. Soc Sci Med. 2002 Feb;54(4):529-44. DOI: https://doi.org/10.1016/S0277-9536(01)00048-X

92. Alam S, Hannon B, Zimmermann C. Palliative care for family caregivers. J Clin Oncol. 2020;38(9):926-36. DOI: https://doi.org/10.1200/JCO.19.00018

93. World Health Organization (WHO). National cancer control programmes: policies and managerial guidelines. Geneva: WHO; 2002.

94. Thomas K, Hudson P, Trauer T, Remedios C, Clarke D. Risk factors for developing prolonged grief during bereavement in family carers of cancer patients in palliative care: a longitudinal study. J Pain Symptom Manag. 2014 Mar;47(3):531-41. DOI: https://doi.org/10.1016/j. jpainsymman.2013.05.022 
95. Samar MA, Rumbold B, Rowting D, Bolleter A, Breen LJ. Bereavement support for family caregivers: the gap between guidelines and practice in palliative care. PLoS One. 2017 Oct;12(10):e0184750. DOI: https:// doi.org/10.1371/journal.pone.0184750

96. Dans M, Kutner JS, Agarwal R, Baker JN, Bauman JR, Beck AC, et al. NCCN guidelines insighnts: palliative care (version 2.2010). J Natl Compr Canc Netw [Internet]. 2021 Jul; [cited 2021 May 20]; 19(7):780-8. Available from: https://www.nccn.org/professionals/ physician_gls/pdf/palliative.pdf

97. Worldwide Palliative Care Alliance (WPCA). Global atlas of palliative care at end of life [Internet]. London: WPCA; 2014; [access in 2021 May 21]. https://www. who.int/nmh/Global_Atlas_of_Palliative_Care.pdf

98. Esperandio MRG, Leget C. Spirituality in palliative care in Brazil: an integrative literature review. Rever. 2020 Sep;20(2):29-45. DOI: https://doi. org/10.23925/1677-1222.2020vol20i2a3

99. Nuzum D, Murphy M. The comfort of nurses and physicians addressing spirituality in palliative care. J Pain Symptom Manag. 2018 Dec;56(6):e141. DOI: https://doi.org/10.1016/j.jpainsymman.2018.10.447

100.Rego F, Nunes R. The interface between psychology and spirituality. Palliat Care. 2019 Aug;24(3):279-87. DOI: https://doi.org/10.1177/1359105316664138

101. Long CO. Cultural and spiritual considerations in palliative care. J Pediatr Hematol Oncol. 2011;33:S96-S101. DOI: https://doi.org/10.1097/MPH.0b013e318230daf3

102. Richardson P. Spirituality, religion and palliative care. Ann Palliat Med. 2014 Jul;3(3):150-9. DOI: https://doi. org/10.3978/j.issn.2224-5820.2014.07.05

103. Steinhauser KE, Balboni TA. State of the science of spirituality and palliative care research: research landscape and future directions. J Pain Symptom Manag. 2017 Sep;54(3):426-7. DOI: https://doi.org/10.1016/j. jpainsymman.2017.02.020

104. Benites AC, Rodin G, Leite ACAB, Nascimento LC, Santos MA. The experience of spirituality in family caregivers of adult and elderly cancer patients receiving palliative care: a meta-synthesis. Eur J Cancer Care. 2021 Feb;30(4):e13424. DOI: https://doi. org/10.1111/ecc.13424
105.Steinhorn DM, Din J, Johnson A. Healing, spirituality and integrative medicine. Ann Palliat Med. 2017;6(3):23747. DOI: https://doi.org/10.21037/apm.2017.05.01

106. Childress JF. The place of autonomy in bioethics. Hastings Center Rep. 1990 Jan/Feb;20(1):12-7. DOI: https://doi.org/10.2307/3562967

107. Gómez-Vírseda C, Maeseneer Y, Gastmans C. Relational autonomy in end-of-life care ethics: a contextualized approach to real-life complexities. BMC Med Ethics. 2020;21(1):50. DOI: https://doi.org/10.1186/s12910020-00495-1

108. Conselho Federal de Medicina (CFM). Resolução CFM $n^{\circ}$ 1995, de 31 de agosto de 2012. Diário Oficial da União, Brasília (DF), 2012 ago 31; Seção 1: 269-70.

109. Conselho Federal de Medicina (CFM). Resolução CFM $N^{\circ} 2.217$, de 27 de setembro de 2018. Diário Oficial da União, Brasília (DF), 01 set 2018; Seção I: 179-82.

110. The Economist - Intelligence Unit. 2015 Quality of death index. The Economist [Internet]. 2015; [access in 2021 May 24]. Available from: https://eiuperspectives. economist.com/healthcare/2015-quality-death-index/ white-paper/2015-quality-death-index?redirect=TRUE

111. Santos CE, Campos LS, Barros NB, Serafim JA, Klug D, Cruz RP. Palliative care in Brasil: present and future. Rev Assoc Med Bras. 2019 Jun;65(6):796. DOI: https:// doi.org/10.1590/1806-9282.65.6.796

112. Academia Nacional de Cuidados Paliativos (ANCP). [Internet]. Sao Paulo: ANCP; ANO; [access in 2022 Jan 27]. Available from: https://api-wordpress.paliativo. org.br/wp-content/uploads/2020/11/10-VIII_congresso_brasileiro_de_cuidados_paliativos_resumos.pdf

113. Cheng MJ, King LM, Alesi ER, Smith TJ. Doing palliative care in the oncology office. J Oncol Pract. 2013;9(2):84. DOI: https://doi.org/10.1200/JOP.2013.000885

114. Hui D, Finlay E, Buss MK, Prommer EE, Bruera E. Palliative oncologists: specialists in the science and art of patient care. J Clin Oncol. 2015;33(20):2314. DOI: https://doi.org/10.1200/JCO.2014.60.3274

115. Jackson VA, Mack J, Matsuyama R, Lakoma MD, Sullivan AM, Arnold RM, et al. A qualitative study of oncologists' approaches to end-of-life care. J Palliat Med. 2008 Aug;11(6):893-906. DOI: https://doi.org/10.1089/ jpm.2007.2480 